\title{
Association of CDKAL1 Genetic Polymorphism with Glycosylated Hemoglobin A1c Level among Non-Diabetic Chinese Adults
}

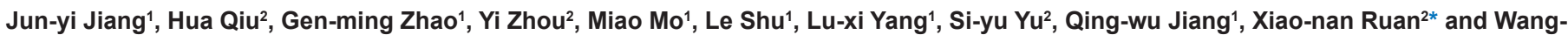
hong $\mathrm{Xu}^{1 *}$

${ }^{1}$ Department of Epidemiology, School of Public Health; Key Laboratory of Public Health Safety, Ministry of Education, Fudan University, 138 Yi Xue Yuan Road, Shanghai, 200032, People's Republic of China

${ }^{2}$ Pudong New Area Centers for Disease Control and Prevention, 3039 Zhang Yang Road, Shanghai 200136, People's Republic of China

\begin{abstract}
Objectives: Multiple single nucleotide polymorphisms (SNPs) have been identified as risk loci for type 2 diabetes (T2DM). This study was conducted to increase our understanding of the mechanisms through which three novel risk variants affect the risk of T2DM.

Methods: 918 Chinese volunteers from Pudong New Area of Shanghai, China, were recruited in Oct-Dec, 2006. Collection of demographic and lifestyle characteristics, body measurements, bio-specimen collection and biochemistry assays were performed during the period. Genotyping of rs290487 at transcription factor 7-like 2 (TCF7L2), rs9465871 at cyclin-dependent kinase 5 regulatory subunit associated protein 1-like 1(CDKAL1) and rs1359790 at chromosome 13q31.1 were conducted using Taqman approach.

Results: Genotypes of TCF7L2-rs290487, CDKAL1-rs9465871 and rs1359790 at $13 q 31.1$ were not associated with metabolic syndrome or its components. While average levels of glycosylated hemoglobin A1c (HbA1c), fasting glucose, serum lipids and anthropometrics did not differ by genotypes of TCF7L2-rs290487 and rs1359790 at 13q31.1, $\mathrm{HbA1c}$ level varied significantly by genotypes of CDKAL1-rs9465871, particularly among women. After adjusting for age, women carrying $C$ allele had a higher level of $\mathrm{HbA} 1 \mathrm{c}$ than those bearing $\mathrm{T}$ allele, with each $\mathrm{C}$ allele linking to appropriate $0.1 \%$ increase of $\mathrm{HbA} 1 \mathrm{c}$ level $(P$ for trend $=0.025)$. However, the difference was no longer significant after multiple comparison correction. Similar patterns were consistently observed regardless of levels of energy, dietary fat and average glycemic index intake ( $P$ for interaction $>0.05)$.
\end{abstract}

Conclusions: CDKAL1-rs9465871 may slightly affect glycemic phenotypes in non-diabetic Chinese women. Our results support the potential role of CDKAL1 gene in the regulation of insulin secretion.

Keywords: Metabolic factors; Single nucleotide polymorphism; Metabolic syndrome

Abbreviations: HbA1c: Glycosylated Hemoglobin A1c; SNP: Single Nucleotide Polymorphism; T2DM: Type 2 Diabetes; TCF7L2: Ranscription Factor 7-like 2; CDKAL1: Cyclin-Dependent Kinase 5 Regulatory Subunit Associated Protein 1-like 1; BMI: Body Mass Index; WHR: Waist To Hip Ratio; SBP: Systolic Blood Pressure; DBP: Diastolic Blood Pressure; TC: Total Cholesterol; TG: Triglyceride; HDLC: High Density Lipoprotein Cholesterol; LDLC: Low Density Lipoprotein Cholesterol; FPG: Fasting Plasma Glucose; GL: Glycemic Load; GI: Glycemic Index; Spry2: Sprouty 2; MAF: Minor Allele Frequency; HWE: Hardy-Weinberg Equilibrium

\section{Introduction}

Type 2 diabetes (T2DM) is a common chronic disease that affects 285 million adults around the world [1]. It is a disease characterized by insulin resistance which is combined with relatively reduced insulin secretion. Both environmental and genetic factors play an important role in the etiology of the disease [2,3]. Obesity, hyperglycemic, dyslipidemia and the condition often termed metabolic syndrome can potentially cause T2DM by inducing insulin resistance and further leading to reduced insulin section [4-6]. The role of genetic factors for T2DM, however, is not clear, particularly for those genetic polymorphisms with low-penetrate.

In recent years, multiple genetic variants have been identified as susceptibility loci for T2DM through genome-wide association studies $[7,8]$. Although some variants have been found to be associated with dysfunction of beta cell, the function remains unclear for many others. Of these variants, three novel genetic polymorphisms may play an important role in susceptibility to T2DM in Chinese population. rs7903146 at the transcription factor 7-like 2 (TCF7L2) gene has been suggested to affect the risk of T2DM by involving the enteroinsular axis, enhanced expression of the gene in islets, modified incretin action and impaired insulin secretion $[9,10]$. Due to the low frequency of the T allele (2\%) in Asian population, the variant seems not an important risk factor for T2DM in the population. Instead, TCF7L2-rs290487, which is in moderate LD with rs7903146 in Chinese Han population $\left(D^{\prime}=1, r^{2}=0.016\right.$, http://www.hapmap.org), was suggested as a main risk variant in Chinese adults [11], but its effect on glucose homeostasis was considered due to insulin resistance[12], much different from that

*Corresponding authors: Wang-hong $\mathrm{Xu}, \mathrm{MD}, \mathrm{PhD}$, Department of Epidemiology, School of Public Health; Key Laboratory of Public Health Safety, Ministry of Education, Fudan University, 138 Yi Xue Yuan Road, Shanghai, 200032, People's Republic of China, E-mail: wanghong.xu@fudan.edu.cn

Xiao-nan Ruan, MD, Pudong New Area Centers for Disease Control and Prevention, 3039 Zhang Yang Road, Shanghai 200136, People's Republic of China, E-mail: ruan_118@hotmail.com

Received October 20, 2011; Accepted December 22, 2011; Published December 26, 2011

Citation: Jiang JY, Qiu H, Zhao GM, Zhou Y, Mo M, et al. (2011) Association of CDKAL1 Genetic Polymorphism with Glycosylated Hemoglobin A1c Leve among Non-Diabetic Chinese Adults. J Diabetes Metab 2:166. doi:10.4172/21556156.1000166

Copyright: (C) 2011 Jiang JY, et al. This is an open-access article distributed under the terms of the Creative Commons Attribution License, which permits unrestricted use, distribution, and reproduction in any medium, provided the original author and source are credited. 
of rs7903146. Risk variants at the cyclin-dependent kinase 5 regulatory subunit associated protein 1-like 1(CDKAL1) gene were associated with insulin-secretory defects and showed little relationship with insulin resistance [13,14]. Recently, C allele of CDKAL1-rs9465871 was observed associated with prevalence of metabolic syndrome and elevated levels of fasting plasma glucose (FPG) and glycosylated hemoglobin A1c (HbA1C) among non-diabetic Japanese, particularly among those with high energy intake [15]. The findings support the role of the gene in regulating insulin secretion. Given the small sample size of the study, however, further researches are warranted to confirm the results. rs 1359790 located at $13 \mathrm{q} 31.1$ is a novel susceptibility single nucleotide polymorphism (SNP) identified by a whole genome scan in Chinese women [8]. Although the SNP has been suggested a tag of Sprouty 2 (Spry2), a gene located at $193 \mathrm{~kb}$ upstream functioning in regulating signal transduction pathways and decreasing $\beta$-cell viability in humans [16], few studies have examined the association of the variant with individuals' metabolic phenotypes.

To better understand the potential functions of these novel genetic polymorphisms of T2DM, we evaluated the associations of TCF7L2-rs290487, CDKAL1-rs9465871 and rs1359790 at 13q31.1 with individual and cluster of metabolic phenotypes among non-diabetic Chinese adults from Pudong New Area of Shanghai, China. Our results may have an implication on the mechanisms through which the three SNPs confer risk to T2DM.

\section{Materials and Methods}

\section{Subjects}

A total of 918 adult volunteers without history of diabetes were recruited from communities of Shanggang, Zhoujiadu, Huamu, Puxing, Weifang, Jinyang, Meiyuan and Jichang in Pudong New Area of Shanghai, China, during the period of Oct- Dec, 2006. None of them were further diagnosed with diabetes according to ADA criteria: 1) fasting plasma glucose $\geq 7.0 \mathrm{mmol} / \mathrm{L}$; or 2) two-hour plasma glucose $\geq 11.1 \mathrm{mmol} / \mathrm{L}$ during an oral glucose tolerance test; 75 -g glucose load should be used; or 3 ) a random plasma glucose concentration $\geq 11.1$ $\mathrm{mmol} / \mathrm{L}$ in persons with symptoms of hyperglycemia or hyperglycemic crisis. The mean age of the subjects was 57.7 (SD, 9.9) years old, and 291(31.7\%) participants were male. The study was approved by Fudan University Institutional Review Board (IRB00002408, FWA00002399).

\section{Data collection}

After obtaining written consent, a structured in-person interview was conducted by trained interviewers to elicit information on demographic characteristics, diagnosis of hypertension, presence of dyslipidemia, use of tobacco and alcohol and dietary habit. Smoking was defined as taking at least 1 cigarette per day for at least 6 months, and alcohol use was defined as drinking alcohol at least 3 times a week for more than 6 months.

Dietary habit was assessed using an interviewer-administered food frequency questionnaire (FFQ) which included 103 foods and food groups commonly consumed in Shanghai. For each food item, participants were asked to report how frequently (daily, weekly, monthly, annually or never) and how long (months per year) they consumed the food, followed by a question on the amount of consumption in liang ( 1 liang $=50 \mathrm{~g}$ ) per unit of time in the previous 12 months. For liquid foods such as milk, juice and beverage, the amount of intake was reported in milliliter $(\mathrm{ml})$ and was transformed into gram in the analysis. The daily intakes of oil, salt and sugar were calculated as the average level consumed by each family member of the participant.

Nutrient content from the Chinese Food Composition Tables was applied to estimate nutrient intake from all food items and groups and, and to obtain glycemic index (GI) values for some foods [17] We also referenced Foster-Powell et al.'s report to obtain GI values for some foods [18]. Each food's glycemic load (GL) was calculated by multiplying the food's GI value by carbohydrate content of the food and the average amount of the food consumed per day. Total dietary GL was then produced by summing these products over all food items. Dietary GI was derived by dividing the dietary GL by the amount of carbohydrate intake, thus yielding a weighted average GI for each individual's diet [19]. We excluded from the analysis the women who had total energy intake $<500 \mathrm{kcal} / \mathrm{d}$ or $>3500 \mathrm{kcal} / \mathrm{d}$ and the men with energy intake of $<800 \mathrm{kcal} / \mathrm{d}$ or $>4000 \mathrm{kcal} / \mathrm{d}$.

\section{Phenotype measurements}

At the interview, each participant was measured for his/her body height, weight, waist circumference, hip circumference, systolic blood pressure (SBP), and diastolic blood pressure (DBP) according to a uniform and standardized protocol. Body mass index (BMI) was calculated as weight $(\mathrm{kg})$ divided by height squared $\left(\mathrm{m}^{2}\right)$. Waist-to-hip ratio (WHR) was also created using measured data.

After at least 10 hours of overnight fasting, a $1 \sim 1.5 \mathrm{ml}$ venous blood specimen was collected in a vacuum tube containing sodium fluoride for the measurement of plasma glucose and HbAlc, and a $3 \sim 3.5 \mathrm{ml}$ non-anticoagulated venous blood specimen was collected for the measurement of total cholesterol (TC), triglyceride (TG), high density lipoprotein cholesterol (HDLC) and low density lipoprotein cholesterol (LDLC).

Enzymology methods were used to measure the fasting plasma glucose level (GOD-PAP), concentrations of TG (GPO-PAP) and TC (CHOD-PAP) on an Automatic Biochemical Analyzer (HITACHI 7170A, Hitachi, Ltd, Tokyo, Japan). Levels of HDLC and LDLC were measured using a selective inhibition method. HbAlc was tested using ion exchange chromatography on DS5 Glycated Hemoglobin Analyzer (DREW DS5, Drew Scientific Co. Ltd, Cumbria, UK). Quality control of the assays was assessed internally and externally. The interassay coefficient of variation was $<1.82 \%$ for FPG (SD $<0.23 \mathrm{mmol} / \mathrm{L})$, $<$ $1.38 \%$ for TG $(\mathrm{SD}<0.02 \mathrm{mmol} / \mathrm{L}),<1.54 \%$ for TC $(\mathrm{SD}<0.08 \mathrm{mmol} / \mathrm{L})$, $<1.6 \%$ for HDLC $(\mathrm{SD}<0.01 \mathrm{mmol} / \mathrm{L}),<5.3 \%$ for LDLC $(\mathrm{SD}<0.21$ $\mathrm{mmol} / \mathrm{L})$, and $<6.13 \%$ for HbAlc $(\mathrm{SD}<0.77)$.

By using the measured data, we identified individuals with metabolic syndrome according to a joint interim statement in 2009 [20] as those having any three of the following five factors: 1$)$ elevated WC ( $\geq 85$ $\mathrm{cm}$ in men and $\geq 80 \mathrm{~cm}$ in women $) ; 2)$ elevated TG $(\geq 1.7 \mathrm{mmol} / \mathrm{L})$, or drug use for elevated TG; 3$)$ reduced HDL-C $(<1.0 \mathrm{mmol} / \mathrm{L}$ in men and $<1.3 \mathrm{mmol} / \mathrm{L}$ in women), or drug use for reduced HDL-C; 4) elevated blood pressure ( $\geq 130 / 85 \mathrm{mmHg}$ ) or antihypertensive drug use for hypertension; and 5) elevated fasting glucose $(\geq 5.6 \mathrm{mmol} / \mathrm{L})$ or drug use for elevated glucose.

\section{DNA genotyping}

Genomic DNA was extracted from leukocyte pellets (100 $\mu \mathrm{l} \mathrm{blood)}$ by proteinase K digestion using Magnetic Genomic DNA kit on Thermo Kingfisher $m l$ machine. TCF7L2-rs290487, CDKAL1-rs9465871 and rs1359790 at 13q31.1 were genotyped by Taqman allelic discrimination assays (assay ID: C_1349543_10 for rs290487; C_29598297_10 for 
Citation: Jiang JY, Qiu H, Zhao GM, Zhou Y, Mo M, et al. (2011) Association of CDKAL1 Genetic Polymorphism with Glycosylated Hemoglobin A1c Level among Non-Diabetic Chinese Adults. J Diabetes Metab 2:166. doi:10.4172/2155-6156.1000166

Page 3 of 7

rs9465871 and C_7442164_10 for rs1359790; Applied Biosystems) on an ABI $7900 \mathrm{HT}$ system.

Genotyping data was obtained for 896 (rs290487), 906 (rs9465871) and 887 (rs359790) subjects, yielding a success rate of 97.6\%, 98.7\% and $96.6 \%$, respectively. The major reason for incomplete genotyping was insufficient quantity of DNA. In addition, $5 \%$ of samples were randomly selected for repeated assays for each SNP and the results were all $100 \%$ consistent.

\section{Statistical analysis}

Statistical analyses were conducted utilizing SAS statistical software 9.2 (SAS Institute Inc., Cary, NC). The deviation of genotype distribution from Hardy-Weinberg equilibrium (HWE) was determined using a fisher exact test. Differences on demographic factors between men and women were evaluated using $\chi^{2}$ test (categorical variables) or non parameter Wilcoxon test (continuous variables). An unconditional logistic regression model was applied to evaluate the association of genetic polymorphisms with metabolic syndrome. A generalized linear regression was applied to compare the average levels of metabolic factors by genotypes of each SNP. Tests for multiplicative interactions were performed by including two main effects and a cross-product term in the regression model. Metabolic phenotypes were natural log (ln) transformed to approximate normal distribution. All statistical tests were based on two-sided probability.

\section{Results}

In this small sample of non-diabetic adults, the minor allele frequency (MAF) was 35.8\% for TCF7L2-rs290487, 46.3\% for CDKAL1-rs9465871 and $27.7 \%$ for rs1359790 at 13q31.1, respectively, which were comparable to those reported in HapMap (http://www. hapmap.org) and several previous studies $[8,11,14]$. The distributions of genotypes at the three loci were all consistent with Hardy-Weinberg Equilibrium (HWE), with a $P$-value of 0.701 for TCF7L2-rs290487, 0.615 for CDKAL1-rs9465871 and 0.837 for rs1359790 at 13q31.1, respectively.

Presented in Table 1 were demographic and clinical characteristics of participants of this study. 291 men and 627 women were similar with respect to body mass index, family history of diabetes, prior history of dyslipidemia, prevalence of metabolic syndrome, measured fasting glucose, TG levels and dietary fat intake. Comparing with the women, the men had an older age, higher WHR, higher levels of measured blood pressures, higher energy intake, higher average GI intake, higher SBP and DBP level, and were more likely to be current smokers or alcohol drinkers. The men appeared to have lower levels of HbAlc, HDLC, LDLC and TC than women. Considering the significant sex difference in demographic and clinical features, we ran most analysis stratified by sex in this study.

As shown in Table 2, the genotype distributions of SNPs rs 290487 , rs9465871 or rs1359790 did not differ between the subjects with and without metabolic syndrome in both men and women (all $P$-value $>$ 0.05). After adjustment for age, no significant association was observed for either one of the three SNPs with metabolic syndrome in both sexes.

Table 3 shows the average levels of HbAlc, fasting glucose, serum lipids and body size by genotypes of TCF7L2-rs290487, rs 1359790 at 13q31.1 and CDKAL1-rs9465871. No significant difference was observed for average level of each measurement among genotypes of TCF7L2-rs290487 and rs1359790 at 13q31.1 in both sexes. However,

\begin{tabular}{|c|c|c|c|}
\hline Characteristics & Men $(n=291)$ & Women $(n=627)$ & $P$-value ${ }^{a}$ \\
\hline \multicolumn{4}{|l|}{ Demographic characteristics } \\
\hline Age, years, mean (SD) & $59.1(10.0)$ & $57.0(9.8)$ & $<0.001$ \\
\hline Education, junior high school or above, n (\%) & $245(84.2)$ & $456(72.7)$ & $<0.001$ \\
\hline Family history of diabetes, $\mathrm{n}(\%)$ & $25(8.6)$ & $63(10.1)$ & 0.485 \\
\hline Prior history of hypertension, n (\%) & $106(36.4)$ & $187(29.8)$ & 0.046 \\
\hline Prior history of dyslipidemia, n (\%) & $20(6.9)$ & $41(6.5)$ & 0.85 \\
\hline Current smoking, $\mathrm{n}(\%)$ & $134(46.1)$ & $6(1.0)$ & $<0.001$ \\
\hline Current alcohol consumption, n (\%) & $113(38.8)$ & $21(3.4)$ & $<0.001$ \\
\hline \multicolumn{4}{|l|}{ Body measurement, mean (SD) } \\
\hline BMI & $25.1(3.1)$ & $25.0(3.3)$ & 0.365 \\
\hline WHR & $0.88(0.06)$ & $0.84(0.06)$ & $<0.001$ \\
\hline $\mathrm{SBP}, \mathrm{mmHg}$ & $134.1(16.4)$ & $129.5(17.1)$ & $<0.001$ \\
\hline $\mathrm{DBP}, \mathrm{mmHg}$ & $85.2(9.0)$ & $81.6(9.6)$ & $<0.001$ \\
\hline \multicolumn{4}{|l|}{ Biochemistry indicators, mean (SD) } \\
\hline Fasting glucose level, mmol/L & $5.4(1.0)$ & $5.3(1.2)$ & 0.101 \\
\hline $\mathrm{HbA} 1 \mathrm{c}, \%$ & $5.9(0.5)$ & $6.0(0.8)$ & 0.023 \\
\hline $\mathrm{HDLC}, \mathrm{mmol} / \mathrm{L}$ & $1.1(0.3)$ & $1.4(0.3)$ & $<0.001$ \\
\hline LDLC, mmol/L & $2.7(0.7)$ & $2.9(0.8)$ & 0.001 \\
\hline $\mathrm{TC}, \mathrm{mmol} / \mathrm{L}$ & $4.3(0.8)$ & $4.6(0.8)$ & $<0.001$ \\
\hline $\mathrm{TG}, \mathrm{mmol} / \mathrm{L}$ & $1.6(1.2)$ & $1.4(0.8)$ & 0.244 \\
\hline \multicolumn{4}{|l|}{ Dietary intake, mean (SD) } \\
\hline Energy, kcal/d & $2019.7(604.7)$ & $1758.6(470.5)$ & $<0.001$ \\
\hline Fat, g/d & $45.3(22.7)$ & $42.0(18.2)$ & 0.139 \\
\hline Average $\mathrm{GI}$ & $62.1(7.8)$ & $60.4(7.3)$ & $<0.001$ \\
\hline Metabolic syndrome, $n$ (\%) & $110(37.8)$ & $249(39.8)$ & 0.568 \\
\hline
\end{tabular}

Missing values ( 3 for HDLC, 14 for dietary factors and 1 for presence of metabolic syndrome) were excluded

${ }^{a} P$ for $\chi^{2}$ test (categorical variables) or non-parameter Wilcoxon test (continuous variables).

Table 1: Comparisons of demographic and clinical characteristics of participants by gender. 
Citation: Jiang JY, Qiu H, Zhao GM, Zhou Y, Mo M, et al. (2011) Association of CDKAL1 Genetic Polymorphism with Glycosylated Hemoglobin A1c Level among Non-Diabetic Chinese Adults. J Diabetes Metab 2:166. doi:10.4172/2155-6156.1000166

Page 4 of 7

a higher level of HbAlc was found among subjects carrying $\mathrm{C}$ allele at CDKAL1-rs9465871, particularly among women. It appeared that each C allele of CDKAL1-rs9465871 was linked to appropriate $0.1 \%$ higher level of HbA1c ( $P$ for trend $=0.025$ ). However, the difference was no longer significant by Bonferroni correction.

To evaluate whether dietary factors could modify the association of CDKAL1-rs9465871 with HbA1c level, we further compared the average level of HbA1c between genotypes at the locus by energy, fat and average GI intake (Figure 1). A similar HbA1c - CDKAL1 rs9465871 associate pattern was observed regardless of levels of intake, with $P$ for interaction tests being 0.900 for energy intake, 0.770 for fat intake and 0.639 for GI intake.

\section{Discussion}

In this small sample of Chinese adults free of diabetes, we did not find significant associations of TCF7L2-rs290487, CDKAL1rs9465871 and rs1359790 at 13q31.1 with metabolic syndrome or any of its components. While the genotypes of TCF7L2-rs290487 and 13q31.1-rs1359790 were not associated with the levels of HbA1c, fasting glucose, serum lipids, and body measurements, the risk allele of CDKAL1-rs9465871 was linked to a slightly elevated HbA1c level, particularly among women.

SNPs of rs290487 at TCF7L2, rs9465871 at CDKAL1 and rs1359790 at $13 \mathrm{q} 31.1$ are three novel susceptibility loci for T2DM. CDKAL1rs9465871 has been suggested to alter the risk of type 2 diabetes predominantly through reduced beta-cell function [13,21], while TCF7L2-rs290487 mainly links to insulin resistance [12]. rs 1359790 at $13 \mathrm{q} 31.1$, on the other hand, is regarded as a tag SNP for Spry2 gene whose function is related with $\beta$-cell viability [16]. In this study, however, none of the three SNPs were associated with metabolic syndrome and related factors. It is believed that the development of metabolic syndrome is mainly initiated with insulin resistance induced by dyslipidemia, whereas the occurrence of T2DM is caused by subsequent severe impaired insulin secretion. It is plausible that the damaged insulin secretion may not be involved in the early stage of

\begin{tabular}{|c|c|c|c|c|c|}
\hline \multirow[b]{2}{*}{ Genotypes } & \multicolumn{2}{|c|}{ Metabolic syndrome } & \multirow{2}{*}{$P$ for $x^{2}$ test } & \multirow[b]{2}{*}{ Age-adjusted OR $(95 \% \mathrm{Cl})^{*}$} & \multirow[b]{2}{*}{$P$ for trend } \\
\hline & Present (\%) & No present (\%) & & & \\
\hline \multicolumn{6}{|l|}{ Men } \\
\hline TCF7L2-rs290487 & & & 0.903 & & 0.631 \\
\hline TT & $48(44.0)$ & $74(41.6)$ & & 1.00 & \\
\hline CT & $50(45.9)$ & $84(47.2)$ & & $1.09(0.66,1.81)$ & \\
\hline $\mathrm{CC}$ & $11(10.1)$ & $20(11.2)$ & & $1.20(0.53,2.73)$ & \\
\hline CDKAL1-rs9465871 & & & 0.850 & & 0.651 \\
\hline $\mathrm{CC}$ & $33(30.3)$ & $53(29.4)$ & & 1.00 & \\
\hline CT & $56(51.4)$ & $89(49.4)$ & & $0.99(0.57,1.72)$ & \\
\hline $\mathrm{TT}$ & $20(18.4)$ & $38(21.2)$ & & $1.20(0.60,2.40)$ & \\
\hline 13q31.1-rs1359790 & & & 0.496 & & 0.306 \\
\hline GG & $58(54.7)$ & $83(47.4)$ & & 1.00 & \\
\hline$A G$ & $39(36.8)$ & $75(42.9)$ & & $1.35(0.81,2.25)$ & \\
\hline $\mathrm{AA}$ & $9(8.5)$ & $17(9.7)$ & & $1.29(0.54,3.11)$ & \\
\hline \multicolumn{6}{|l|}{ Women } \\
\hline TCF7L2-rs2904987 & & & 0.984 & & 0.976 \\
\hline $\mathrm{TT}$ & $96(40.3)$ & $149(40.3)$ & & 1.00 & \\
\hline CT & $111(46.6)$ & $171(46.2)$ & & $0.98(0.68,1.40)$ & \\
\hline $\mathrm{CC}$ & $31(13.0)$ & $50(13.5)$ & & $1.00(0.59,1.71)$ & \\
\hline CDKAL1-rs9465871 & & & 0.343 & & 0.827 \\
\hline $\mathrm{CC}$ & $66(26.9)$ & $113(30.5)$ & & 1.00 & \\
\hline $\mathrm{CT}$ & $127(51.8)$ & $170(45.8)$ & & $0.77(0.52,1.14)$ & \\
\hline $\mathrm{TT}$ & $52(21.2)$ & $88(23.7)$ & & $0.98(0.61,1.56)$ & \\
\hline 13q31.1-rs1359790 & & & 0.247 & & 0.107 \\
\hline GG & $120(49.4)$ & $201(55.5)$ & & 1.00 & \\
\hline AG & $103(42.4)$ & $140(38.7)$ & & $0.85(0.60,1.20)$ & \\
\hline $\mathrm{AA}$ & $20(8.2)$ & $21(5.8)$ & & $0.58(0.30,1.14)$ & \\
\hline
\end{tabular}

*OR, odds ratio; $95 \% \mathrm{Cl}, 95 \%$ confidence interval.

Table 2: Associations of genotypes of TCF7L2-rs290487, CDKAL1-rs9465871 and rs1359790 at 13q31.1 with metabolic syndrome. 
Citation: Jiang JY, Qiu H, Zhao GM, Zhou Y, Mo M, et al. (2011) Association of CDKAL1 Genetic Polymorphism with Glycosylated Hemoglobin A1c Level among Non-Diabetic Chinese Adults. J Diabetes Metab 2:166. doi:10.4172/2155-6156.1000166

Page 5 of 7

\begin{tabular}{|c|c|c|c|c|c|c|c|c|c|c|c|c|}
\hline \multirow{2}{*}{$\begin{array}{l}\text { Metabolic } \\
\text { factors }^{\dagger}\end{array}$} & \multicolumn{3}{|c|}{ TCF7L2-rs290487 } & \multirow{2}{*}{$\begin{array}{c}P \\
\text { Value* }\end{array}$} & \multicolumn{3}{|c|}{ 13q31.1-rs1359790 } & \multirow{2}{*}{$\begin{array}{c}P \\
\text { Value* }^{*}\end{array}$} & \multicolumn{3}{|c|}{ CDKAL1-rs9465871 } & \multirow{2}{*}{$\begin{array}{c}P \\
\text { Value* }\end{array}$} \\
\hline & $\mathrm{TT}$ & CT & $\mathrm{CC}$ & & AA & AG & GG & & TT & CT & $\mathrm{CC}$ & \\
\hline Men, $N$ & 122 & 134 & 31 & & 26 & 114 & 141 & & 58 & 145 & 86 & \\
\hline $\mathrm{FPG}, \mathrm{mmol} / \mathrm{L}$ & $5.4(1.2)$ & $5.3(1.2)$ & $5.3(1.1)$ & 0.800 & $5.3(1.2)$ & $5.3(1.1)$ & $5.4(1.2)$ & 0.583 & $5.1(1.1)$ & $5.4(1.2)$ & $5.5(1.2)$ & 0.072 \\
\hline $\mathrm{HbA} 1 \mathrm{c}, \%$ & $5.9(1.1)$ & $5.9(1.1)$ & $5.8(1.1)$ & 0.757 & $5.9(1.1)$ & $5.9(1.1)$ & $5.9(1.1)$ & 0.887 & $5.8(1.1)$ & $5.9(1.1)$ & $5.9(1.1)$ & 0.384 \\
\hline $\mathrm{TC}, \mathrm{mmol} / \mathrm{L}$ & $4.2(1.2)$ & $4.3(1.2)$ & $4.3(1.2)$ & 0.461 & $4.3(1.2)$ & $4.3(1.2)$ & $4.2(1.2)$ & 0.497 & $4.1(1.2)$ & $4.3(1.2)$ & $4.3(1.2)$ & 0.222 \\
\hline $\mathrm{TG}, \mathrm{mmol} / \mathrm{L}$ & $1.3(1.8)$ & $1.4(1.7)$ & $1.1(1.8)$ & 0.209 & $1.2(1.6)$ & $1.3(1.8)$ & $1.3(1.8)$ & 0.933 & $1.3(1.8)$ & $1.3(1.8)$ & $1.4(1.7)$ & 0.672 \\
\hline LDLC, mmol/L & $2.6(1.3)$ & $2.7(1.3)$ & $2.7(1.3)$ & 0.543 & $2.6(1.3)$ & $2.7(1.3)$ & $2.6(1.3)$ & 0.502 & $2.5(1.4)$ & $2.7(1.3)$ & $2.6(1.3)$ & 0.135 \\
\hline $\mathrm{HDLC}, \mathrm{mmol} / \mathrm{L}$ & $1.1(1.3)$ & $1.1(1.3)$ & $1.1(1.2)$ & 0.952 & $1.2(1.3)$ & $1.1(1.2)$ & $1.1(1.3)$ & 0.101 & $1.1(1.3)$ & $1.1(1.3)$ & $1.1(1.3)$ & 0.979 \\
\hline BMI & $25.2(1.1)$ & $24.8(1.1)$ & $24.5(1.1)$ & 0.504 & $25.9(1.1)$ & $24.7(1.1)$ & $25.0(1.1)$ & 0.224 & $24.9(1.2)$ & $24.9(1.1)$ & $25.0(1.1)$ & 0.983 \\
\hline WHR & $0.88(1.1)$ & $0.88(1.1)$ & $0.88(1.1)$ & 0.936 & $0.90(1.1)$ & $0.88(1.1)$ & $0.88(1.1)$ & 0.353 & $0.88(1.1)$ & $0.88(1.1)$ & $0.88(1.1)$ & 0.873 \\
\hline Women, $N$ & 245 & 283 & 81 & & 41 & 244 & 321 & & 140 & 298 & 179 & \\
\hline $\mathrm{FPG}, \mathrm{mmol} / \mathrm{L}$ & $5.2(1.2)$ & $5.3(1.2)$ & $5.3(1.2)$ & 0.806 & $5.3(1.1)$ & $5.3(1.2)$ & $5.2(1.2)$ & 0.846 & $5.2(1.1)$ & $5.3(1.2)$ & $5.3(1.2)$ & 0.261 \\
\hline $\mathrm{HbA} 1 \mathrm{c}, \%$ & $5.9(1.1)$ & $6.0(1.1)$ & $6.0(1.1)$ & 0.545 & $6.0(1.1)$ & $6.0(1.1)$ & $6.0(1.1)$ & 0.872 & $5.9(1.1)$ & $6.0(1.1)$ & $6.1(1.1)$ & 0.025 \\
\hline $\mathrm{TC}, \mathrm{mmol} / \mathrm{L}$ & $4.6(1.2)$ & $4.5(1.2)$ & $4.5(1.2)$ & 0.765 & $4.5(1.3)$ & $4.6(1.2)$ & $4.5(1.2)$ & 0.757 & $4.7(1.2)$ & $4.5(1.2)$ & $4.5(1.2)$ & 0.034 \\
\hline TG, mmol/L & $1.2(1.7)$ & $1.2(1.7)$ & $1.3(1.6)$ & 0.578 & $1.2(1.6)$ & $1.3(1.7)$ & $1.2(1.6)$ & 0.575 & $1.3(1.7)$ & $1.2(1.7)$ & $1.2(1.7)$ & 0.108 \\
\hline LDLC, mmol/L & $2.8(1.3)$ & $2.8(1.3)$ & $2.8(1.4)$ & 0.914 & $2.8(1.4)$ & $2.8(1.3)$ & $2.8(1.3)$ & 0.894 & $2.9(1.3)$ & $2.8(1.3)$ & $2.8(1.3)$ & 0.121 \\
\hline $\mathrm{HDLC}, \mathrm{mmol} / \mathrm{L}$ & $1.3(1.3)$ & $1.3(1.3)$ & $1.3(1.3)$ & 0.391 & $1.3(1.2)$ & $1.3(1.3)$ & $1.3(1.3)$ & 0.784 & $1.3(1.3)$ & $1.3(1.3)$ & $1.3(1.3)$ & 0.712 \\
\hline BMI & $24.4(1.1)$ & $25.0(1.1)$ & $25.0(1.1)$ & 0.106 & $25.4(1.1)$ & $24.8(1.1)$ & $24.8(1.1)$ & 0.374 & $25.2(1.1)$ & $24.7(1.1)$ & $24.6(1.1)$ & 0.293 \\
\hline WHR & $0.84(1.1)$ & $0.84(1.1)$ & $0.83(1.1)$ & 0.525 & $0.85(1.1)$ & $0.84(1.1)$ & $0.83(1.1)$ & 0.219 & $0.83(1.1)$ & $0.84(1.1)$ & $0.84(1.1)$ & 0.491 \\
\hline
\end{tabular}

† Continuous variables were expressed as Mean (S.D.)

* Generalized linear model adjusted age.

Table 3: Average level of metabolic factors by genotypes of TCF7L2-rs290487, rs1359790 at 13q31.1 and CDKAL1-rs9465871.
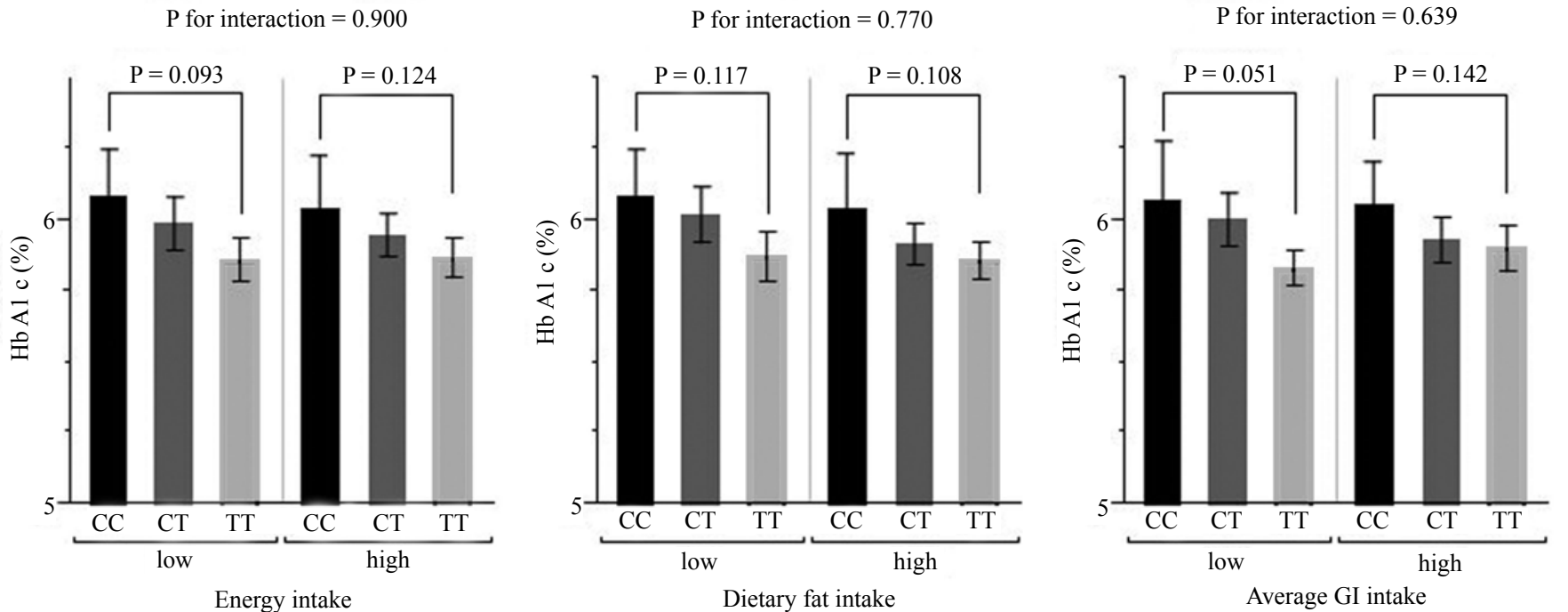

Figure 1: Average level of $\mathrm{HbA1c}$ in subjects with different genotypes at CDKAL1-rs9465871 by the levels of energy, fat and average GI intake. The groups of low or high intake were classified by the medians of intake. The medians were $1756.3 \mathrm{kcal} / \mathrm{d}$ for energy intake, $39.7 \mathrm{~g} / \mathrm{d}$ for dietary fat intake and 60.7 for average $\mathrm{Gl}$ intake.

metabolic syndrome, and the genetic factors involving insulin secretion may not be associated with the disorder in non-diabetic adults. Therefore, our results suggest that, if the risk alleles at the SNPs confer risk to T2DM in Chinese adults, they may be linked to impairment of insulin secretion rather than a defect in peripheral insulin action.
Although we did not evaluate the association of TCF7L2-rs290487 with T2DM, the null association between the variant and metabolic syndrome is somewhat supported by several studies focusing on other T2DM susceptibility loci at TCF7L2 gene [22,23]. In a case-control study in Mexico, Cruz et al. [22] observes a strong association of C allele 
at TCF7L2 rs12255372 with T2DM, but a null relation with metabolic syndrome. Saadi et al. [23] also finds that TCF7L2-rs12255372 is associated with T2DM but not with metabolic syndrome. However, we did not observe the effect of TCF7L2-rs290487 on glucose level, which is not consistent with several studies. In Liu et al. report[12], TCF7L2-rs290487 C allele is significantly associated with a higher glucose concentrations, a higher insulin concentration and a lower insulin sensitivity index, but not with the measures of insulin secretion in 525 Taiwanese adolescent twin-pairs and siblings. Each $\mathrm{C}$ allele of TCF7L2 -rs7903146 is associated with $0.054 \%$ decrease of HbA1c level in healthy populations in a GWAS meta-analysis [24], and the T allele is linked to a higher level of the long-term index of glucose level in other two studies $[25,26]$.

In this study, rs1359790 at 13q31.1 was not associated with metabolic syndrome and $\mathrm{HbAlc}$ level either. The result is consistent with a large scale case-control study recently conducted in Japan, in which rs 1359790 is observed to be associated with T2DM but not with any metabolic phenotypes [27]. More studies are needed to assess the role of the locus and related mechanisms in the development of T2DM among Chinese population.

Interestingly, unlike TCF7L2-rs290487 and rs1359790 at 13q31.1, the risk allele at CDKAL1-rs9465871 is observed associated with elevated $\mathrm{HbAlc}$ level. $\mathrm{HbAlc}$ concentration is a long-term indicator of the level of plasma glucose and it has been recently used as one of criteria to detect diabetes [28]. In our subjects, each C allele at CDKAL1 rs 9465871 was related with appropriate $0.1 \%$ increase in $\mathrm{HbAlc}$ level. The result is consistent with the finding of Miyaki et al. [15], but with a difference of that the effect of the variant was observed among women in our study but among men in Miyaki's report [15]. The smaller number of male subjects may account for the difference. However, we could not exclude the contribution of possible genetic heterogeneity between men and women [29], and between Chinese and Japanese population.

CDKAL1 gene encodes the CDK5 regulatory subunit-associated protein 1-like 1 . The protein product of the gene shares homology with cyclin-dependent kinase 5 regulatory subunit-associated protein, a neuronal protein that can specifically inhibit activation of CDK5 [30]. CDK5 has been shown to act on the beta-cell dysfunction under glucotoxic conditions and to reduce the sensitivity of insulin secretion in response to glucotoxity, and the inhibition of this protein can prevent the decrease of insulin gene expression [31]. Therefore, it is plausible that if a certain variant at CDKAL1 gene can alter the function of beta cells, it will lead to changes of insulin level in blood and ultimately the increase in HbA1c level. Our results suggest that, due to its effect on glycemic phenotype in health adults, CDKAL1-rs9465871 may be a sensitive susceptibility locus of T2DM in Chinese population.

To test whether the association of rs9465871-HbA1c can be modified by dietary factors, as reported by Miyaki et al. [15], we further evaluated the association stratified by intake of dietary energy, fat and average GI, respectively. We did not find that the association pattern between genotypes at rs9465871 and HbAlc was dependent on the intake level of these dietary factors, which is not consistent with Miyaki et al. report [15]. It is possible that the power in this study is not enough to evaluate the potential interactions. On the other hand, the positive interaction observed in Japanese may be false positive, as a result of information bias, small sample size and multiple comparisons [32].
Strengths of this study include rigorously measured variables using standard protocols and vigorous quality control in data collection and lab assays. However, the small sample size in this study may have limited our ability to examine the effect of the three SNPs on HbAlc level, particularly among men. Under an additive model, $\alpha=0.05$ and $\mathrm{OR}=1.2$, the power was $83.40 \%$ for TCF7L2-rs290487, $85.60 \%$ for CDKAL1-rs9465871 and $77.90 \%$ for 13q31.1-rs1359790 in overall analysis. In stratified analysis by sex, however, the power was less than $80 \%$ in both men and women. This also may have led to lacking power to assess the potential modifying effect of dietary intake. Further studies with a large sample size are needed to confirm our results.

In summary, no significant associations were observed for TCF7L2rs290487, rs1359790 at 13q31.1 and CDKAL1-rs9465871 with metabolic phenotypes in this small Chinese population, indicating a potential role of the three novel susceptibility loci, if any, in the regulation of insulin secretion. The effect of CDKAL1-rs9465871 on HbA1c level in Chinese non-diabetic adults implicates its role as a susceptible marker for T2DM in the population.

\section{Acknowledgments}

This research was funded by Shanghai Municipal Health Bureau (08GWZX0201) and Academic Leaders Training Program of Pudong Health Bureau of Shanghai (Grant No. PWRd2010-03). JYJ contributed to data collection data analysis and draft of the paper. $\mathrm{HQ}, \mathrm{YZ}$ and SYY contributed to data collection and quality control. MM, LS and LXY contributed to DNA extracting and genotyping GMZ and QWJ contributed to revision of the paper. XNR and WHX contributed to study design, statistical analysis and revision of the paper. The authors are grateful to the study participants and research staff from Community Health Centers in Pudong New Area of Shanghai, China.

\section{References}

1. Shaw JE, Sicree RA, Zimmet PZ (2010) Global estimates of the prevalence of diabetes for 2010 and 2030. Diabetes Res Clin Pract 87: 4-14.

2. Riserus U, Willett WC, Hu FB (2009) Dietary fats and prevention of type 2 diabetes. Prog Lipid Res 48: 44-51.

3. Ripsin CM, Kang H, Urban RJ (2009) Management of blood glucose in type 2 diabetes mellitus. Am Fam Physician 79: 29-36.

4. Getz GS, Reardon CA (2010) High-density lipoprotein function in regulating insulin secretion: possible relevance to metabolic syndrome. Arterioscler Thromb Vasc Biol 30: 1497-1499.

5. Chen G, Liu C, Yao J, Jiang Q, Chen N, et al. (2010) Overweight, obesity, and their associations with insulin resistance and beta-cell function among Chinese: a cross-sectional study in China. Metabolism 59: 1823-1832.

6. Nolan CJ, Damm P, Prentki M (2011) Type 2 diabetes across generations: from pathophysiology to prevention and management. Lancet 378: 169-181.

7. Wheeler E, Barroso I (2011) Genome-wide association studies and type 2 diabetes. Brief Funct Genomics 10: 52-60.

8. Shu XO, Long J, Cai Q, Qi L, Xiang YB, et al. (2010) Identification of new genetic risk variants for type 2 diabetes. PLoS Genet 6: e1001127.

9. Lyssenko V, Lupi R, Marchetti P, Del GS, Orho-Melander M, et al.(2007) Mechanisms by which common variants in the TCF7L2 gene increase risk of type 2 diabetes. J Clin Invest 117: 2155-2163.

10. Villareal DT, Robertson H, Bell GI, Patterson BW, Tran H, et al. (2010) TCF7L2 variant rs7903146 affects the risk of type 2 diabetes by modulating incretin action. Diabetes 59: 479-485.

11. Chang YC, Chang TJ, Jiang YD, Kuo SS, Lee KC, et al. (2007) Association study of the genetic polymorphisms of the transcription factor 7-like 2 (TCF7L2) gene and type 2 diabetes in the Chinese population. Diabetes 56: 2631-2637.

12. Liu PH, Chang YC, Jiang YD, Chen WJ, Chang TJ, et al. (2009) Genetic 
Citation: Jiang JY, Qiu H, Zhao GM, Zhou Y, Mo M, et al. (2011) Association of CDKAL1 Genetic Polymorphism with Glycosylated Hemoglobin A1c Level among Non-Diabetic Chinese Adults. J Diabetes Metab 2:166. doi:10.4172/2155-6156.1000166

variants of TCF7L2 are associated with insulin resistance and related metabolic phenotypes in Taiwanese adolescents and Caucasian young adults. $\mathrm{J}$ Clin Endocrinol Metab 94: 3575-3582.

13. Perry JR, Frayling TM (2008) New gene variants alter type 2 diabetes risk predominantly through reduced beta-cell function. Curr Opin Clin Nutr Metab Care 11: 371-377.

14. Wu Y, Li H, Loos RJ, Yu Z, Ye X, et al. (2008) Common variants in CDKAL1, CDKN2A/B, IGF2BP2, SLC30A8, and HHEX/IDE genes are associated with type 2 diabetes and impaired fasting glucose in a Chinese Han population. Diabetes 57: 2834-2842.

15. Miyaki K, Oo T, Song Y, Lwin H, Tomita Y, et al. (2010) Association of a cyclindependent kinase 5 regulatory subunit-associated protein 1-like 1 (CDKAL1) polymorphism with elevated hemoglobin $A(c)$ levels and the prevalence of metabolic syndrome in Japanese men: interaction with dietary energy intake. Am J Epidemiol 172: 985-991.

16. Frank MJ, Dawson DW, Bensinger SJ, Hong JS, Knosp WM, et al. (2009) Expression of sprouty2 inhibits B-cell proliferation and is epigenetically silenced in mouse and human B-cell lymphomas. Blood 113: 2478-2487.

17. Yang YX, Wang GY, Pan XC (2002) China Food Composition Tables 2002. Beijing University Medical Press.

18. Foster-Powell K, Holt SH, Brand-Miller JC (2002) International table of glycemic index and glycemic load values: 2002. Am J Clin Nutr 76: 5-56.

19. Liu S, Manson JE, Stampfer MJ, Holmes MD, Hu FB, et al. (2001) Dietary glycemic load assessed by food-frequency questionnaire in relation to plasma high-density-lipoprotein cholesterol and fasting plasma triacylglycerols in postmenopausal women. Am J Clin Nutr 73: 560-566.

20. Alberti KG, Eckel RH, Grundy SM, Zimmet PZ, Cleeman JI, et al. (2009) Harmonizing the metabolic syndrome: a joint interim statement of the International Diabetes Federation Task Force on Epidemiology and Prevention; National Heart, Lung, and Blood Institute; American Heart Association; World Heart Federation; International Atherosclerosis Society; and International Association for the Study of Obesity. Circulation 120: 1640-1645.

21. Wu Y, Li H, Loos RJ, Yu Z, Ye X, et al. (2008) Common variants in CDKAL1, CDKN2A/B, IGF2BP2, SLC30A8, and HHEX/IDE genes are associated with type 2 diabetes and impaired fasting glucose in a Chinese Han population. Diabetes 57: 2834-2842.
22. Cruz M, Valladares-Salgado A, Garcia-Mena J, Ross K, Edwards M, et al. (2010) Candidate gene association study conditioning on individual ancestry in patients with type 2 diabetes and metabolic syndrome from Mexico City. Diabetes Metab Res Rev 26: 261-270.

23. Saadi H, Nagelkerke N, Carruthers SG, Benedict S, Abdulkhalek S, et al (2008) Association of TCF7L2 polymorphism with diabetes mellitus, metabolic syndrome, and markers of beta cell function and insulin resistance in a population-based sample of Emirati subjects. Diabetes Res Clin Pract 80: 392 398.

24. Franklin CS, Aulchenko YS, Huffman JE, Vitart V, Hayward C, et al. (2010) The TCF7L2 diabetes risk variant is associated with $\mathrm{HbA}(\mathrm{C})$ levels: a genome-wide association meta-analysis. Ann Hum Genet 74: 471-478.

25. Kimber CH, Doney AS, Pearson ER, McCarthy MI, Hattersley AT, et al. (2007) TCF7L2 in the Go-DARTS study: evidence for a gene dose effect on both diabetes susceptibility and control of glucose levels. Diabetologia 50: 11861191.

26. Karns R, Zhang G, Jeran N, Havas-Augustin D, Missoni S, et al. (2011) Replication of genetic variants from genome-wide association studies with metabolic traits in an island population of the Adriatic coast of Croatia. Eur $J$ Hum Genet 19: 341-346.

27. Imamura M, Iwata M, Maegawa H, Watada H, Hirose H, et al. (2011) Genetic variants at CDC123/CAMK1D and SPRY2 are associated with susceptibility to type 2 diabetes in the Japanese population. Diabetologia 54: 3071-3077.

28. American Diabetes Association (2011) Diagnosis and classification of diabetes mellitus. Diabetes Care 34 Suppl 1: S62-S69.

29. Ryoo H, Woo J, Kim Y, Lee C (2011) Heterogeneity of genetic associations of CDKAL1 and HHEX with susceptibility of type 2 diabetes mellitus by gender. Eur J Hum Genet 19: 672-675.

30. Lew J, Huang QQ, Qi Z, Winkfein RJ, Aebersold R, et al. (1994) A brain-specific activator of cyclin-dependent kinase 5. Nature 371: 423-426.

31. Ubeda M, Rukstalis JM, Habener JF (2006) Inhibition of cyclin-dependent kinase 5 activity protects pancreatic beta cells from glucotoxicity. J Biol Chem 281: 28858-28864

32. Franks PW, Nettleton JA (2010) Invited commentary: Gene X lifestyle interactions and complex disease traits--inferring cause and effect from observational data, sine qua non. Am J Epidemiol 172: 992-999. 